\title{
Tick-borne encephalitis increasing in Sweden, 2011
}

A Lundkvist (ake.lundkvist@smi.se) $)^{1,2,3}$, A Wallensten ${ }^{1,3}$, S Vene $^{1}$, M Hjertqvist $^{1}$

1. Swedish Institute for Communicable Disease Control, Solna, Sweden

2. Karolinska Institutet, Stockholm, Sweden

3. Uppsala University, Uppsala, Sweden

Until August, 161 cases of tick-borne encephalitis (TBE) were recorded in Sweden for 2011, leading to an incidence of 1.7 per 100,000 population. Fifty to 59 year-olds (24\%) were most affected, $55 \%$ of the cases were males. An increase in TBE in Sweden has occurred in the last decade and might be explained by enlarged tick populations, more contact between TBE virus infected ticks and man, and also by growing awareness of the disease. Climatic conditions may have contributed to the increase.

Until 25 September 2011, two hundred and four patients have been diagnosed as tick-borne encephalitis (TBE) cases, indicating that 2011 may be a record year for the number of TBE cases in Sweden.

\section{Background}

Tick-borne encephalitis virus (TBEV) belongs to the Flavivirus family, which includes a number of other important human pathogens such as yellow fever, Japanese encephalitis, West Nile and dengue viruses. TBEV is transmitted to man by ticks (Ixodes ricinus and I. persulcatus) and is found in three subtypes; the European, the Siberian and the Far Eastern subtypes. The European subtype is present in Sweden, and the first clinical TBE case was recorded in 1954 and the virus was isolated in 1959 [1,2]. In Sweden, as well as in other countries around the Baltic sea, TBE is endemic in the coastal regions, but cases also occur around lakes in southern Sweden and on the Swedish west coast (Figure 1). In Norway and Denmark, TBEV was first described as late as in 2006 [3].

Human infection with TBEV may cause a potentially serious neurological disease. The vast majority of those who are infected will have mild or no symptoms, while in patients with more marked clinical illness, high fever and encephalitis may occur [4]. About 46 per cent of diagnosed patients suffer permanent neurological sequelae. The case fatality rate in Europe is less than two per cent [5].

Reliable laboratory diagnostics have been available since the mid 1950 s and the disease has been notifiable

\section{FIGURE 1}

Location of tick-borne encephalitis cases in Sweden, 2010

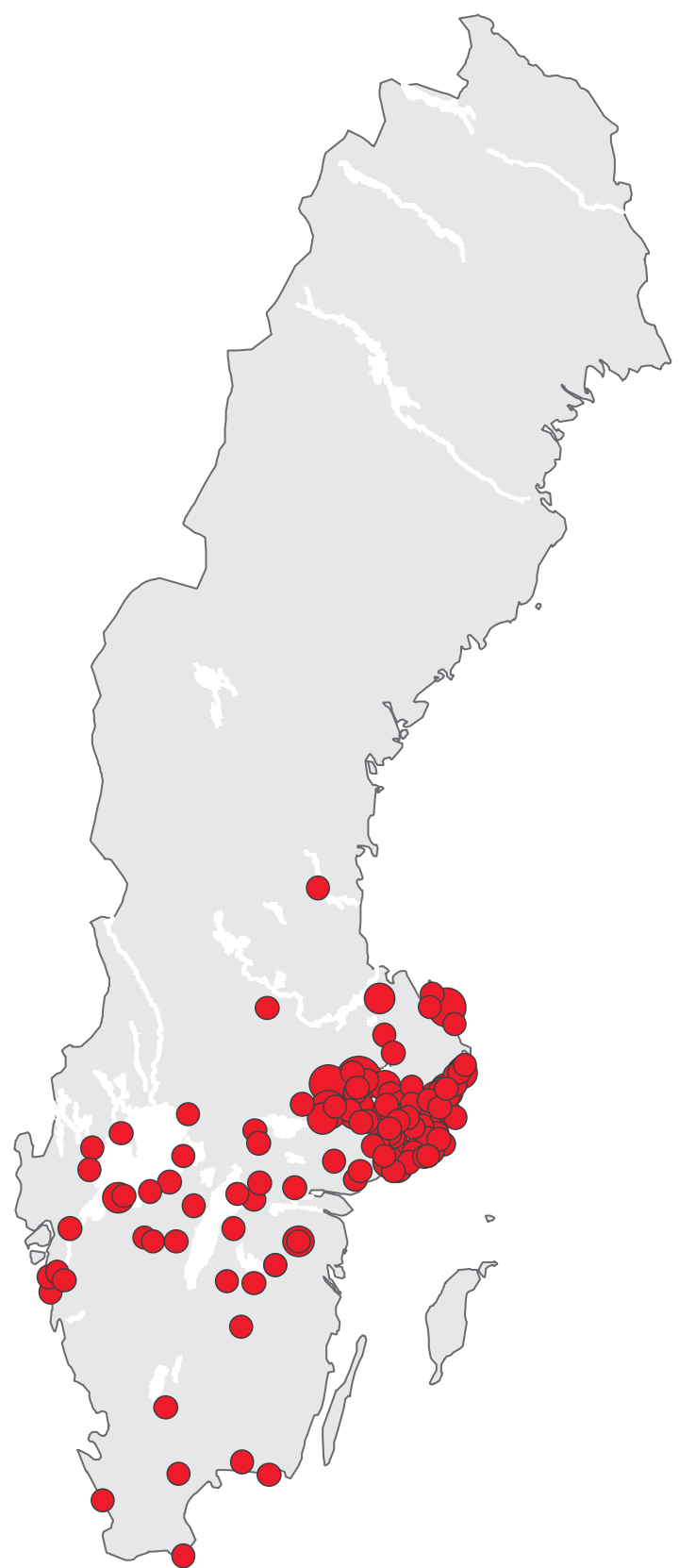

The red dots show probable geographical location of infection for the cases. 
by reporting to the Swedish Institute for Communicable Disease Control (SMI) since 1969. TBE is reported on the basis of clinical neurological symptoms and compulsory laboratory confirmation. The number of cases was quite stable during the 1960 s and 1970s, but has increased from the mid-1980s (Figure 2).

\section{Vaccination}

Vaccination was introduced in Sweden in 1988. Three doses are needed for protection [6]. Vaccination is not subsidised and is only recommended for people living or spending time in "high risk areas" (mainly the coastal areas of the counties of Uppsala and Södermanland, the Stockholm archipelago, around the Mälaren lake, and some local foci around the Vänern and Vättern lakes). TBE vaccination is not registered in Sweden, but the yearly number of sold doses (approximately 500,000) indicates that the vaccine coverage is still low. Only a few investigations on vaccine coverage have been performed, suggesting a maximum of $30 \%$ vaccinees in Stockholm county.

\section{Increase in Swedish tick-borne encephalitis cases}

Between 1956 and 1984, the yearly number of TBE cases in Sweden ranged from less than 10 to a maximum of 50. During the period from 1985 to 1999 , the average number of yearly cases was 63 . The number of individuals infected by TBEV has increased during the last 11 years (Figure 2). Until August 2011, 161 cases of TBE have been recorded in Sweden for 2011, leading to an incidence of 1.7 per 100,000 population for the whole country. Since TBE is restricted to some parts of the country, the incidences for the Södermanland, Uppsala and Stockholm counties are much higher, 9.29, 6.55 and 3.71 , respectively. In August only, 83 cases were reported, which is more than during any other month during the past four years. Up to 25 September 2011, a total of 204 cases of TBE has already been reported for 2011, compared to a total of 174 for the whole of 2010 (2009:210, 2008: 224). The age group comprising 50 to 59 year-olds was the most affected (24\%) and $55 \%$ of the cases were males. The age and sex-ratios were similar to previous years (Figure 3 ).

\section{FIGURE 2}

Number of yearly tick-borne encephalitis cases in Sweden, January 1956-September 2011ª $(n=3,648)$

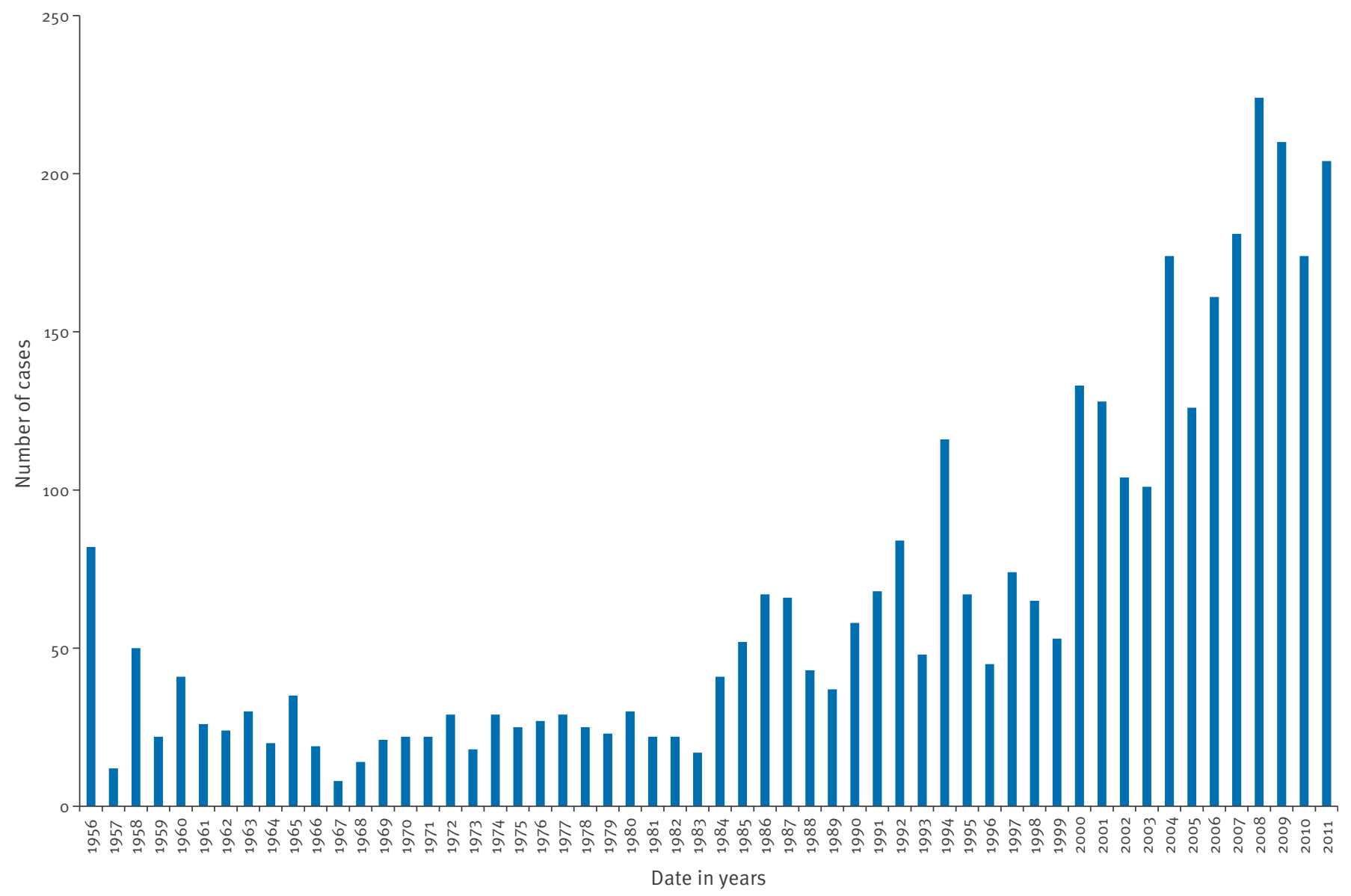

As the notification system has varied over the years (notifiable since 1969), the number of cases is not completely comparable over the whole time period.

a Data up to 25 September 2011. 


\section{Discussion and conclusions}

In 2011, Sweden has seen an increase in notification of TBE cases up to 25 September that amounts to numbers amongst the highest recorded. Normally, additional cases are also reported in October, indicating that 2011 may be a record year concerning TBE in Sweden.

In our opinion, a potential explanation for the increase of TBE cases in Sweden during the last years is a general increase of the tick population ( $T$ Jaenson, personal communication, 26 September 2011), although human behaviour and contact with wildlife could also have contributed.

Factors that help tick populations thrive are among others, non-extreme temperatures, high humidity and the presence of snow cover during the winter, which acts as insulation. The last decades' increased mean annual temperature [7] may have provided more favourable conditions for ticks. In particular, the last years' ample snow cover, early springs with rapidly increasing temperatures as well as the not too hot or dry summers may have been important positive factors for tick survival and reproduction success [8,9]. However, climatic factors alone may not be sufficient to contribute to an increase of the tick-population. The density of the most important blood sources, e.g. rodents, deer or hares, is also important.

Factors concerning human exposure to ticks may be favourable weather and abundance of mushrooms or berries which stimulates outdoor activities. In recent years, springs have been warmer than before [10], the summers and autumns have been relatively warm, all of which are likely to have increased human exposure to ticks.

In conclusion, we believe that weather is likely to have stimulated both tick populations and human exposure resulting in an increase in human cases in 2011 in Sweden.

\section{FIGURE 3}

Age and sex distribution of tick-borne encephalitis cases, Sweden, 2006-2010 (n=954)

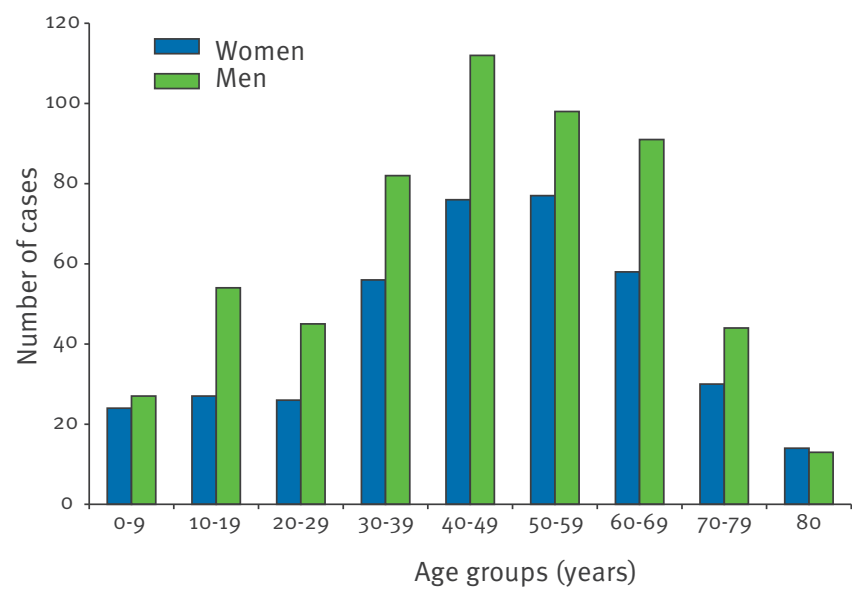

Acknowledgments

Prof. L. Lindquist, Stockholm, and Prof. T Jaenson, Uppsala, are greatly acknowledged for most valuable information and discussions.

References

1. Holmgren B, Lindahl J, von Zeipel G, Svedmyr A. Tick-borne meningoencephalomyelitis in Sweden. Acta Med Scand. 1959;164:507-22.

2. von Zeipel G. Isolation of viruses of the Russian SpringSummer Encephalitis-Louping Ill group from Swedish ticks from a human case of meningoencephalitis. Arch Gesamte Virusforsch. 1959;9:460-9.

3. Skarpaas T, Golovljova I, Vene S, Ljostad U, Sjursen H, Plyusnin A, et al. Tickborne encephalitis virus, Norway and Denmark. Emerg Infect Dis. 2006;12(7):1136-8.

4. Ruzek D, Dobler G, Donoso Mantke O. Tick-borne encephalitis: pathogenesis and clinical implications. Travel Med Infect Dis. 2010;8(4):223-32.

5. Haglund M, Gunther G. Tick-borne encephalitis--pathogenesis, clinical course and long-term follow-up. Vaccine. 2003;21 Suppl 1:S11-8.

6. Vaccines against tick-borne encephalitis: WHO position paper - Recommendations. Who Publication. Vaccine. Forthcoming 2011 Jul.

7. Swedish Meteorological and Hydrological Institute (SMHI). Stockholms temperaturserie [Stockholm's temperature series]. Swedish. [Accessed 26 Sep 2011]. Available from: http://www.smhi.se/klimatdata/meteorologi/temperatur/ stockholms-temperaturserie-1.2847

8. Burri C, Bastic V, Maeder G, Patalas E, Gern L. Microclimate and the zoonotic cycle of tick-borne encephalitis virus in Switzerland. J Med Entomol. 2011 May;48(3):615-27.

9. Jaenson T. Antalet fästingar ökar i Sverige [Increased tick abundance in Sweden]. Epi-Aktuellt. 2011; 10(28): 2-3. Swedish. Available from: http://www.smi.se/ publikationer/smis-nyhetsbrev/epi-aktuellt/epi-aktuellt-2011/ epi-aktuellt-vol-10-nr-28-14-juli-2011-/\#p19589

10. Swedish Meteorological and Hydrological Institute (SMHI). Klimatindikator - temperatur [Climate indicator Temperature]. Swedish. . [Accessed 26 Sep 2011]. Available from: http://www.smhi.se/klimatdata/meteorologi/ temperatur/1.2430 